\title{
Cross-coupling of Vinyl Cuprates and Allylic Halides and Synthesis of the Comstock Mealybug Pheromone via
}

\section{Photooxidation of 2,6-Dimethyl-2,5-heptadiene}

\author{
PETER BAECKSTRÖM, FREDRIK BJÖRKLING, HANS-ERIK HÖGBERG * and \\ TORBJÖRN NORIN
}

Department of Organic Chemistry, Royal Institute of Technology, S-100 44 Stockholm, Sweden

Lithium bis(2-methylpropenyl)cuprate (4) generated with tetrabutylammonium (TBA) $\mathrm{Cu}(\mathrm{I}) \mathrm{Br}_{2}$ (3) from 2-methylpropenyl lithium (2) was coupled with 3-methyl-1-bromo-2-butene $(5 b)$ to form 2,6-dimethyl-2,5-heptadiene (6). Photooxidation of 6 in the presence of $\mathrm{TBABH}_{4}$ and selective acetylation gave the pheromone of the Comstock mealybug 2,6-dimethyl-1,5-heptadiene-3-ol acetate (9).

The synthesis of 1,4-dienes is of particular interest for the synthesis of natural products of the long-chain type, including certain pheromones. ${ }^{1}$ We have chosen 2,6-dimethyl-2,5-heptadiene (6) as a model for the preparation of such systems by cross-coupling vinylic cuprates and allylic halides. The choice was influenced by our interest in applying our newly developed method for photooxidation in the presence of tetrabutylammonium (TBA) borohydride ${ }^{2}$ to diene 6 . The reason for this was that one of the expected products would be 2,6-dimethyl-1,5-heptadien-3-ol $(7)^{3}$, the corresponding acetate (9) of which has been

* Present address: Department of Chemistry, University College of Sundsvall/Härnösand, P.O. Box 860, S-851 24 Sundsvall, Sweden. identified as a pheromone of the Comstock mealybug, Pseudococcus comstocki (Kuwana) by two independent groups. ${ }^{4,5}$ In both cases the structure elucidation of the pheromone was verified by synthesis. In one case yields were not mentioned ${ }^{4}$ and in the other case the overall yield was $\approx 9 \% .^{5 \mathrm{~b}}$ The optical rotation and the absolute configuration of the natural pheromone released by virgin females have been determined to be $(R)-(+)$ by chiral synthesis. ${ }^{6}$ In field tests however, the naturally occurring pheromone and the synthetic racemate caused approximately the same number of catches. ${ }^{4}$ The racemic acetate 9 is thus suitable as a lure in traps.

Our cuprate mediated cross-coupling route to diene 6 is depicted in Scheme 1. In order to avoid unwanted formation of 1,3-dienes by homocoupling of vinylic cuprates, it is necessary that no $\mathrm{Cu}$ (II)-species or oxygen are present. ${ }^{7}$ As a source of pure $\mathrm{Cu}(\mathrm{I})$ we selected the recently described TBA dibromocuprate $(I)^{8}(3)$ for making the divinylic cuprate 4 .

In comparison with allylic bromides the corresponding allylic chlorides are more stable and less apt to cis-trans-isomerize. Hence we initially tried to couple cuprate 4 with 1-chloro-3-methyl-

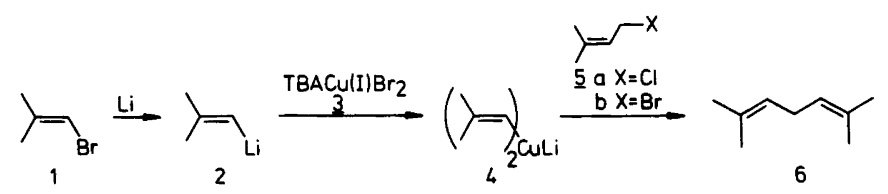

Scheme 1. 
2-butene (5a). Although some coupling was observed in diethyl ether the reaction was too slow to be useful. The corresponding bromide $(5 b)$ on the other hand gave diene 6 in close to quantitative yield based on the vinylic lithium 2, which was formed in 70-90\% yield from the bromide 1 (vide infra).

The homo-coupling product, 2,5-dimethyl-2,4hexadiene, amounted to less than $2 \%$ of the final reaction mixture and no trace of the product anticipated from an allylic rearrangement ( $c f$. Ref. 9) of the electrophile $5 b$ was present as judged by capillary GC.

Coupling of the vinylic lithium reagent 2 with the allylic bromide $5 b$ was also tried in the absence of $\mathrm{Cu}(\mathrm{I})$ ( $c f$. Ref. 10). In this case a very slow formation of the cross coupling product was observed. In the presence of 0.5 equivalents of $\mathrm{TBACu}(\mathrm{I}) \mathrm{Br}_{2}(3)$ on the other hand, the reaction rapidly went to completion in a close to quantitative yield calculated on the amount of vinylic lithium compound 2 formed. This amount was estimated by quenching with water and subsequent GC determination of the ratio between vinylic bromide 1 and 2-methylpropene. This means that both the vinylic groups of cuprate 4 can be transferred under mild conditions ( $c f$. Ref. 11).

Our route to the mealybug pheromone (9) is outlined in Scheme 2. Photooxidation of 2,6dimethyl-2,5-heptadiene (6) in chloroform in the presence of $\mathrm{TBABH}_{4}{ }^{2}$ and subsequent treatment of the crude reaction mixture with acetic anhydride and pyridine selectively acetylated the secondary alcohol 7. The desired acetate 9 was then easily separated by liquid chromatography. The alcohols 7 and 8 could also be separated by chromatography prior to acetylation but such a procedure offers no advantage. Due to unfavourable product distribution and secondary product formation the overall yield of the racemic pheromone 9 was only $\approx 10 \%$. This result is in accord with a report on a conventional photooxidation of diene 6 which appeared after the initiation of this work. ${ }^{12}$ In spite of the low yield, the described method makes the racemic pheromone of the Comstock mealybug available by simple operations.

\section{EXPERIMENTAL}

${ }^{1} \mathrm{H}$ NMR spectra were recorded in $\mathrm{CDCl}_{3}$ on a Bruker WP 200 or a JEOL PMX-60 spectrometer. A Finnigan model 4021 connected to an INCOS data system was used to record GC-MS spectra. Analytical GC was performed on a PYE 204 instrument with an FID detector using fused silica capillary columns. Liquid chromatography was performed with Merck silica gel $0.040-0.063$ mm dry packed in $2.54 \mathrm{~cm}$ i.d. columns unless specified. The solvent, light petroleum b.p. $40-60{ }^{\circ} \mathrm{C}$ with increasing amounts of ethyl acetate $(0,0.63,1.25,1.88,2.5,3.75,5.00,7.5,10$, $15,20,30,40,60,80 \%$ ) was delivered with a metering pump at a rate of $60 \mathrm{ml} / \mathrm{min}$. A "poor man's" gradient mixer was arranged as follows: The suction tube of the pump was placed in a stirred vessel initially containing pure light petroleum and portions of solvent of increased polarity were successively delivered to the surface of the liquid in the vessel by a stoppered dropping funnel. All fractions $(30 \mathrm{ml})$ were examined by TLC. TLC was performed on silica gel (Merck 60, precoated aluminium foil) eluted with $20 \%$ ethyl acetate in light petroleum. Spraying with vanillin in ethanol containing sulfuric acid and heating to $140^{\circ} \mathrm{C}$ visualized the compounds. Irradiations were performed in

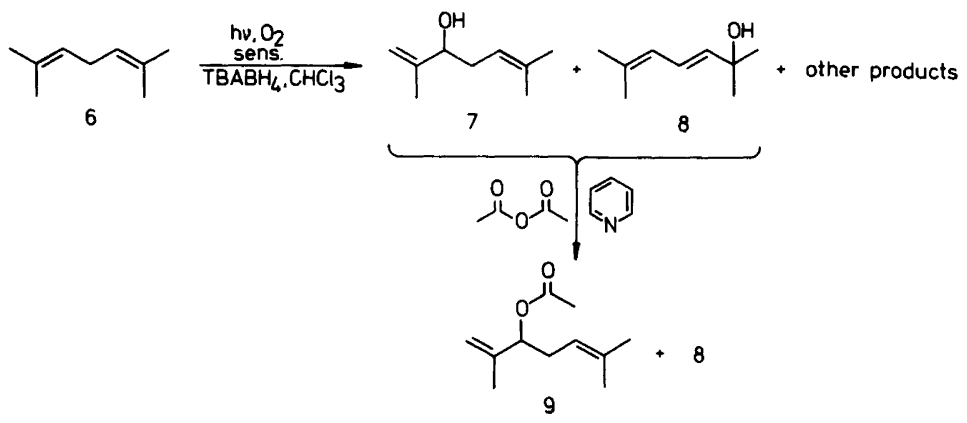

Scheme 2. 
Pyrex vessels using a Rayonet reactor with 16 RPR $350 \mathrm{~nm}$ lamps, employing the procedure for photooxidation in the presence of $\mathrm{TBABH}_{4}$ described earlier. ${ }^{2}$ The coupling reactions were performed strictly under argon atmosphere and all transfers were made via a double-ended needle or a syringe.

2,6-Dimethyl-2,5-heptadiene (6). ${ }^{13}$ 1-Bromo-2methyl-1-propene $(1){ }^{14}(3.2 \mathrm{~g}, 23.7 \mathrm{mmol})$ in dry ethyl ether $(30 \mathrm{ml})$ was slowly added to finely cut lithium metal ( $0.36 \mathrm{~g}, 2.1$ eq., sodium content $4.25 \%)$ in ethyl ether $(60 \mathrm{ml})$ at $-25^{\circ} \mathrm{C}$. The temperature was kept below $-15^{\circ} \mathrm{C}$ throughout the lithiation which was monitored by withdrawing samples that were quenched with water. The ratio of the starting bromide (1) and the formed 2-methyl propene was determined by GC with a $25 \mathrm{~m} \mathrm{SE}-30$ capillary column. The lithiation was complete after $2 \mathrm{~h}$ and the solution was transferred to a suspension of $\left.\mathrm{TBACu}^{\mathrm{I}}\right) \mathrm{Br}_{2}(3)^{8}(5.26 \mathrm{~g}$, $12.1 \mathrm{mmol})$ in ethyl ether $(100 \mathrm{ml})$ at $-70^{\circ} \mathrm{C}$. Then 1-bromo-3-methyl-2-butene $(5 b)(2.9 \mathrm{~g}$, $19.4 \mathrm{mmol})$ in ethyl ether $(20 \mathrm{ml})$ was added. The coupling reaction went to completion in a few minutes and was worked up by addition of a saturated aqueous solution of ammonium chloride at $-70^{\circ}$, extraction with ethyl ether, washing the ether with brine, drying $\left(\mathrm{MgSO}_{4}\right)$ and filtering through silica gel. Careful removal of the solvent gave $2.4 \mathrm{~g}$ of a product which was shown by GLC to be $98.5 \%$ pure $(99 \%$ based on the allylic bromide $5 b$ ). Spectral data were consistent with those published earlier. ${ }^{13}$

Photooxidation of 2,6-dimethyl-2,5-heptadiene (6). Isolation of 2,6-dimethyl-1,5-heptadien-3-ol (7) and 2,6-dimethyl-3,5-heptadien-2-ol (8). 2,6Dimethyl-2,5-heptadiene (6) $(0.950 \mathrm{~g}, 7.66$ mmol), $\mathrm{TBABH}_{4}(2.00 \mathrm{~g})$ and dodecane $(0.264$ g) as internal standard were dissolved in chloroform $(90 \mathrm{ml})$ containing TBA-solubilized rose bengal ( $1.5 \mathrm{~g}$ rose bengal and $0.96 \mathrm{~g} \mathrm{TBABr} / 1)$. The reaction mixture was irradiated with oxygen bubbling through the solution and the disappearance of starting material was monitored by GC ( $25 \mathrm{~m} \mathrm{SE}-54$ capillary column). At $65 \%$ conversion of starting material ( $75 \mathrm{~min}$ ) the irradiation was stopped and additional $\mathrm{TBABH}_{4}(0.5 \mathrm{~g})$ was added. After $30 \mathrm{~min}$ the chloroform was removed in vacuo. Addition of potassium iodide $(2.5 \mathrm{~g})$, water $(3 \mathrm{ml})$ and ethyl ether $(25 \mathrm{ml})$ caused TBA-iodide to precipitate. After $2 \mathrm{~h}$ of stirring the precipitate was removed by filtration and washed with ethyl ether. Washing the ether with brine, drying $\left(\mathrm{MgSO}_{4}\right)$ and solvent removal gave a red viscous residue which was adsorbed on silica gel $(5 \mathrm{~g})$ and chromatographed on a $33 \mathrm{~cm}$ column topped with neutral alumina $(0.5 \mathrm{~cm})$ to retain the dye. Fractions 32-34 contained 2,6-dimethyl-1,5-heptadien-3-ol (7) $(0.117 \mathrm{~g}$, $10.9 \%)$ and fractions $36-40,2,6$-dimethyl-3,5heptadien-2-ol $(8)^{15,16}(0.255 \mathrm{~g}, 23.8 \%)$. Recorded spectral data for compound 7: $\mathrm{MS},{ }^{4 \mathrm{~b}}$ IR $^{3,5 b, 6} \mathrm{NMR}^{3,56,6}$ Compound $8{ }^{1} \mathrm{H}$ NMR 200 MHz: $\delta 6.44(1 \mathrm{H}$, dd, $J 10.8$ and $15.3 \mathrm{~Hz}$, $=\mathrm{CH}-\mathrm{CH}=\mathrm{CH}-), 5.81[1 \mathrm{H}$, additional allyl coupling, $\left.J 10.8 \mathrm{~Hz},\left(\mathrm{CH}_{3}\right)_{2}=\mathrm{CH}-\mathrm{CH}=\right], 5.71$ $\left[1 \mathrm{H}, \mathrm{d}, \mathrm{J} 15.3 \mathrm{~Hz},\left(\mathrm{CH}_{3}\right)_{2} \mathrm{OH}--\mathrm{CH}=\mathrm{CH}-\right]$, $1.78[6 \mathrm{H}, \mathrm{s}$, additional allyl coupling, $\left.\left(\mathrm{CH}_{3}\right)_{2}=\mathrm{CH}-\right], 1.34$ [6H, s, $\left.\left(\mathrm{CH}_{3}\right)_{2} \mathrm{OH}-\right], 1.41$ variable $(1 \mathrm{H}, \mathrm{s},-\mathrm{OH})$.

2,6-Dimethyl-1,5-heptadien-3-ol acetate (9) via selective acetylation of the crude photolysate of 2,6-dimethyl-2,5-heptadiene (6). The diene 6 (2.5 g) and $\mathrm{TBABH}_{4}(5.2 \mathrm{~g})$ were dissolved in chloroform $(90 \mathrm{ml})$ containing TBA-solubilized rose bengal and the solution was irradiated $(150$ min) as described above. Additional $\mathrm{TBABH}_{4}$ $(1.5 \mathrm{~g})$ was added and after $30 \mathrm{~min}$ the reaction mixture was worked up, using potassium iodide $(6.7 \mathrm{~g})$, water $(10 \mathrm{ml})$ and ethyl ether $(100 \mathrm{ml})$. After solvent removal pyridine $(5 \mathrm{ml})$ and acetic anhydride $(5 \mathrm{ml})$ were added to the crude reaction mixture. After $3 \mathrm{~h}$ at ambient temperature brine $(25 \mathrm{ml})$ was added and the reaction mixture extracted with light petroleum $(3 \times 25$ $\mathrm{ml}$ ). Drying and solvent removal gave a pyridine smelling residue which was adsorbed on silica gel $(10 \mathrm{~g})$ and chromatographed on a $33 \mathrm{~cm}$ column. This gave $0.337 \mathrm{~g}(9.2 \%)$ of the racemic pheromone 9 with spectral data in agreement with those published earlier. ${ }^{4-6}$

Acknowledgements. This work is part of the joint research project "Odour Signals for Control of Pest Insects" sponsored by various funds including the Swedish research councils. Financial support for the purchase of chromatographic equipment from Axel och Margaret Ax:son Johnsons Stiftelse is gratefully acknowledged. We also thank Professor M. Nilsson for interesting discussions on organocopper chemistry.

\section{REFERENCES}

1. Henrick, C. A. Tetrahedron 33 (1977) 1845.

2. Baeckström, P., Okecha, S., De Silva, N., Wijekoon, D. and Norin, T. Acta Chem. Scand. B. 36 (1982) 31.

3. Shono, T., Yoshimura, T. and Oda, R. J. Org. Chem. 32 (1967) 1088.

4. a. Bierl-Leonhardt, B. A., Moreno, D. S., Schwarz, M., Forster, H. S., Plimmer, J. R. and DeVilbiss, E. D. Life Sci. 27 (1980) 399; b. Bierl-Leonhardt, B. A., Moreno, D. S., 
Schwarz, M., Forster, H. S., Plimmer, J. R. and DeVilbiss, E. D. J. Chem. Ecol. 8 (1982) 689.

5. a. Negishi, T., Uchida, M., Tamaki, Y., Mori, K., Ishiwatari, T., Asano, S. and Nakagawa, K. Appl. Entomol. Zool. 15 (1980) 328; b. Uchida, M., Nakagawa, K., Negishi, T., Asano, S. and Mori, K. Agric. Biol. Chem. 45 (1981) 369.

6. Mori, K. and Ueda, H. Tetrahedron 37 (1981) 2581.

7. Theis, A. B. and Townsend, C. A. Synth. Commun. 11 (1981) 157.

8. Nilsson, M. Acta Chem. Scand. B 36 (1982) 125.

9. van Mourik, G. L. and Pabon, H. J. J. Tetrahedron Lett. (1978) 2705.

10. Linstrumelle, G. Tetrahedron Lett. (1974) 3809.

11. Alexakis, A., Cahiez, G. and Normant, J. F. Synthesis (1979) 826.

12. Carless, H. A. J. and Batten, R. J. Tetrahedron Lett. (1982) 4735.

13. Zilenovski, J. S. R. and Hall, S. S. J. Org. Chem. 44 (1979) 1159.

14. Braude, E. A. and Evans, E. A. J. Chem. Soc. (1955) 3324

15. Braude, E. A. and Coles, J. A. J. Chem. Soc. (1952) 1425

16. Smith, I. H. and Casida, J. E. Tetrahedron Lett. (1981) 203.

Received January 30, 1984. 